\title{
Saberes, territórios e uso de drogas: modos de vida na rua e reinvenção do cuidado
}

\author{
Knowledge, territories, and drug use: \\ street ways of life and reinventing care
}

Lorena Silva Marques (https://orcid.org/0000-0001-5491-8587) ${ }^{1}$

José Hermógenes Moura da Costa (https://orcid.org/0000-0002-4617-1839) ${ }^{2}$

Marla Marcelino Gomes (https://orcid.org/0000-0002-8573-7372) ${ }^{3}$

Martha Malaquias da Silva (https://orcid.org/0000-0002-0397-5984) ${ }^{4}$

${ }^{1}$ Programa de PósGraduação em Psicologia, Universidade Federal do

Rio Grande do Norte. Campus Universitário Lagoa

Nova, Caixa Postal 1622 59078-970 Natal RN Brasil. lorenasmarqs@gmail.com

${ }^{2}$ Colegiado de Ciências Sociais, Universidade Federal do Vale do São Francisco. Juazeiro BA Brasil.

${ }^{3}$ Setor de Atenção Básica, Secretaria Municipal de Saúde de Petrolina. Petrolina PE Brasil.

${ }^{4}$ Programa de Mestrado

Profissional de Sociologia em Rede Nacional,

Universidade Federal do

Vale do São Francisco.

Petrolina PE Brasil.
Abstract Through the stigmatization of drug-using People Living on the Streets (PLS) and the reproduction of violence in health services, this paper reflected on this community and the street space beyond the view of decrepitude with which they are usually seen. In this sense, the research contours were shaped from the objective of knowing practice and knowledge constructed in the care processes among the drug-using PLS. A qualitative study was designed, using the triangulation of participant observation techniques, from the inclusion of one of the researchers in a "Street Clinic" (Consultório na Rua), in an inland city of the state of Pernambuco, Brazil, and two types of in-depth individual interviews: the episodic interview and the narrative interview. Three thematic categories were outlined from the data retrieved, as follows: "subjects, territorialities and contexts", "drugs, social problem medicalization, and control", and "harm reduction, singularities and care production in the territory". Thus, understandings about the norms and dichotomies that cross the view of PLS were constructed to consolidate the care offer guided by the perspective of harm reduction.

Key words Homeless persons, Drug users, Harm reduction
Resumo Mediante o processo de estigmatização existente sobre a População em Situação de Rua que faz uso de drogas e a reprodução de violências nos serviços de saúde, refletiu-se neste artigo sobre esse público e o espaço da rua para além da visão de decrepitude com que costumeiramente são vistos. Nesse sentido, a pesquisa tomou contornos a partir do objetivo de conhecer práticas e saberes construídos nos processos de cuidado entre a População em Situação de Rua usuária de drogas. Para isso, delineou-se um estudo qualitativo, utilizando-se da triangulação das técnicas de observação participante, a partir da inserção de uma das pesquisadoras em um Consultório na Rua, em uma cidade no interior de Pernambuco, e duas modalidades de entrevistas individuais em profundidade: a entrevista episódica e a entrevista narrativa. A partir dos dados obtidos, delineou-se três categorias temáticas: "Sujeitos, territorialidades e contextos", "Drogas, medicalização de problemas sociais e controle" e "Redução de danos, singularidades e produção de cuidado no território". Construíram-se, assim, compreensões sobre as normativas e dicotômicas que atravessam a visão sobre a População em Situação de Rua, pretendendo contribuir para a consolidação da oferta de cuidado orientada pela perspectiva da Redução de Danos. Palavras-chave Pessoas em situação de rua, Usuários de drogas, Redução de danos 


\section{Introdução}

Deslocando as construções identitárias instituídas ao escaparem às relações que ditam o universo do trabalho e da casa, a População em Situação de Rua (PSR) denuncia a falsa autonomia que perpassou o ideário de liberdade alimentado na Idade Média em relação à construção das cidades. Dessa forma, evidenciam como as organizações sociais nesse espaço são antidemocráticas, subtraindo a existência de gurpos sociais em decorrência de interesses econômicos ${ }^{1}$.

A expansão do número de pessoas em situação de rua no país se dá em meados do século XX, em decorrência de fatores diversos, alcançando sujeitos em processos migratórios decorrentes da industrialização, desempregados, com problemas associados ao uso problemático de drogas, egressos do sistema penitenciário, entre outros. Atualmente, esse cenário tem se intensificado mediante o fortalecimento da política neoliberal no país, responsável pelo aumento do desemprego e a fragilização de políticas públicas que garantam direitos sociais fundamentais, desdobrando-se em uma crescente criminalização da probreza ${ }^{2}$.

Processo que pode ser visto na estigmatização da PSR enquanto "vagabundas, sujas, loucas, perigosas e coitadas"3. Goffman", ao falar sobre estigma, o aborda enquanto um fenômeno constituído socialmente, a partir dos quais são estabelecidos formas de classificação, tendo-se a categoria dos considerados normais e pessoas ou grupos que destoam dessas construções, sofrendo processos de estigmatização.

É a partir dessas construções que se fabrica o imaginário social sobre a PSR, o que atravessa a identidade desses sujeitos, reproduzindo relações de opressão ${ }^{3}$. A visão dicotômica e excludente que as sustentam os colocam em um lugar de decrepitude, reduzindo o olhar sobre a complexidade e a diversidade que compõe o espaço da rua ${ }^{5}$.

Diante disso, propomos neste estudo refletir sobre o espaço da rua para além do lugar de carência e privação ${ }^{5}$, considerando a importância dessa abordagem para complexificação do olhar sobre os processos de produção de cuidado. É necessária a compreensão sobre a possibilidade de construção de outros territórios existenciais que esse espaço possibilita, permitindo a PSR a reinvenção dos modos de lidar consigo e com o mundo da rua ${ }^{5}$.

Dentro dessas compreensões, é de extrema importância também a complexificação do olhar sobre o uso de drogas na contemporaneidade, uma das grandes demandas encontradas entre a PSR. O uso de drogas está entre um dos fatores mais determinantes para a ida desses sujeitos para a rua ${ }^{6}$, bem como é responsável pelo lugar de dupla estigmatização em que grande parcela dessa população é colocada ${ }^{7}$.

Contexto que se relaciona à própria constituição da psiquiatria enquanto saber e poder institucionalizados. Segundo Foucault ${ }^{8}$, com a criação da noção de anormalidade, e uma compreensão sobre um comportamento "normal", foi possível a essa forma de saber capturar a loucura enquanto problema médico. Teve-se, assim, a institucionalização da dita normalidade.

Entretanto, modificações nesses modos de controle foram necessárias na contemporaneidade devido a organização de sociedades capitalistas. As medidas disciplinares do século XIX se tornaram insuficientes para o agenciamento dos modos de viver, de modo que deram lugar a emergência da ideia de autogestão dos sujeitos sobre suas próprias vidas?.

Contudo, não se percebe a existência de dispositivos que operam de modo a permitir que a produção de subjetividade se desdobre em territórios identitários específicos, não podendo desdobrar-se em qualquer tipo de subjetivação. Coloca-se o que foge aos padrões estabelecidos enquanto expressão de adoecimento, de forma que o desejo dos sujeitos passa a ser criminalizado a partir da indicação do que são práticas saudáveis?.

Compreensões perpassadas também pela guerra ideológica contra as drogas no século XX, as quais buscaram negar a existência do uso de substâncias que alteram os estados de consciência de forma milenar e universal ${ }^{10}$. Nesse sentido, o que se criminaliza verdadeiramente é a busca por novos territórios existenciais. Tem-se, dessa forma, processos de assujeitamento contra pessoas que utilizam drogas a partir da fabricação imagética do lugar de capturados pela dependência ${ }^{9}$.

$\mathrm{Na}$ contramão dessas práticas, defende-se neste estudo a perspectiva da Redução de Danos (RD) enquanto guia para a oferta do cuidado as pessoas que fazem uso de drogas. Em especial dentro da Rede de Atenção Psicossocial (RAPS), instituída pela portaria $3.088 / 11^{11}$, em que são estabelecidos os pontos de atenção para o atendimento de pessoas em sofrimento psíquico, incluindo os efeitos nocivos do uso de drogas, compreendendo a atenção básica em saúde, atenção psicossocial especializada e atenção a urgência e emergência.

Em contraposição à perspectiva da $\mathrm{RD}$, que norteava a política do Ministério da Saúde para 
a Atenção Integral aos Usuários de Álcool e outras Drogas (portaria no 2.197/04) ${ }^{12}$, o governo Bolsonaro, através do decreto $9.761 / 19^{13}$, institui uma "nova" política de drogas, que tem enquanto eixo norteador a abstinência, representando um retrocesso dentro da Reforma Psiquiátrica, que luta pelos direitos sociais e o cuidado em liberdade $^{14}$.

Um dos fundamentos norteadores da RD é a possibilidade de potencialização das estratégias que minimizem os danos à saúde em decorrência do uso de drogas. A RD "considera a relevância de entender a complexidade que permeia o fenômeno da utilização de substâncias psicoativas, desde as diferentes modalidades de uso, às peculiaridades dos sujeitos e das culturas nas quais estão inseridos" (p. 99) ${ }^{7}$.

Nesse sentido, pontua-se a importância da compreensão sobre como o uso de drogas atravessa os processos identitários de grande parcela da PSR, influenciando na invenção de outros modos de organização. Busca-se, assim, a apreensão dos saberes construídos nas reterritorializações forjadas no intenso caminhar da PSR ${ }^{15}$, e o reconhecimento do que se desdobra enquanto possibilidade de cuidado.

Compreendendo-se que essas construções se dão dentro de um espaço e tempo, enquanto elaboração do experienciado em uma realidade material, social e cultural estabelecida, que configura um campo de possibilidades para o sujeito. Considerando-se que as estruturas sociais não são determinantes das ações humanas, mas a forma singular como são vivenciados por cada sujeito se desdobra entrelaçada ao significado objetivo de um fenômeno sociocultural ${ }^{16}$.

\section{Percurso metodológico}

Pretendendo preservar a historicidade dos sujeitos e grupos envolvidos, a pesquisa assumiu um caráter de natureza qualitativa, considerando esta uma metodologia sensível aos contextos situacionais concretos em que o fenômeno se constitui ${ }^{17}$. A realização da pesquisa se deu por meio da triangulação das técnicas de observação participante e duas modalidades de entrevistas individuais em profundidade: a entrevista episódica ${ }^{18} \mathrm{e}$ a entrevista narrativa ${ }^{19}$.

O processo de observação participante ocorreu a partir da inserção de uma das pesquisadoras no Consultório na Rua (CnaR), em uma cidade localizada no interior do estado de Pernambuco, no sertão do submédio São Francisco, durante o estágio de prática da Residência Multiprofissional em Saúde Mental, da Universidade Federal do Vale do São Francisco.

Considera-se que esse tipo de intervenção possibilita acessar conhecimentos sobre o grupo a partir da vivência em seu interior, permitindo o acesso a informações que não seriam disponibilizadas facilmente ${ }^{20}$. Ela ocorreu durante um período de seis meses, em dois dias na semana, durante o horário de funcionamento do serviço. Para o registro do experienciado, foram escritos diários de campo.

Por sua vez, a entrevista narrativa permitiu o esquadrinhamento de contextos sócio-históricos a partir da experiência dos sujeitos, possibilitando o conhecimento de histórias de vida. Já em relação as entrevistas episódicas, considerou-se que elas possibilitaram colocar em termos concretos a ideia da triangulação interna ao método, combinando os enfoques narrativo e argumentativo, permitindo a compreensão sobre situações e relações dos colaboradores com os dispositivos de saúde.

As entrevistas foram realizadas com quatro homens e uma mulher, utilizando-se como critério para a escolha dos participantes três condições: estar em situação de rua, considerar fazer uso problemático de drogas e aceitar participar das entrevistas. As entrevistas duraram em média 50 minutos, ocorrendo em diversos contextos, de acordo com a disponibilidade dos colaboradores. Mediante autorização, as falas foram gravadas através de um aparelho celular, sendo posteriormente transcritas para análise e armazenada em arquivos digitais. No intuito de preservar a identidade dos usuários, nomes fictícios foram utilizados na apresentação dos dados.

Para a construção dos resultados, foram utilizados os seis passos que compõem a proposta de Schütze para a análise de entrevistas ${ }^{19}$, os quais permitiram a reconstituição das trajetórias de cada sujeito e a identificação das opiniões, conceitos e teorias gerais, reflexões e divisões entre o comum e o incomum. A comparação das informações organizadas a partir desse processo possibilitou a identificação de trajetórias coletivas, correlacionadas com o referencial teórico, possibilitando a estruturação de três categorias temáticas. 


\section{Resultados e discussão}

\section{Sujeitos, territorialidades e contextos}

Para a compreensão do fenômeno de utilização da rua enquanto espaço de vivência e sobrevivência, faz-se imprescindível entender a diversidade de circuitos percorridos que antecedem essa situação-limite ${ }^{15}$. O entendimento sobre os processos que levam a PSR ao contexto de vulnerabilidade em que se encontram, bem como o reconhecimento das suas especificidades e potencialidades, permite não só a complexificação do olhar sobre a análise do funcionamento da sociedade $^{21}$, como também sobre a heterogeneidade existente entre esse público ${ }^{22}$.

Caminhos habitualmente margeados por idas e vindas a rua, perdas de conexões familiares, passagem por diversos trabalhos, entre outras constantes $^{15}$. Castel ${ }^{23}$ aponta que compreender a diversidade existente entre aqueles que são marginalizados se faz fundamental para que estes não sejam colocados no mesmo patamar de exclusão.

Nesse sentido, faz-se importante para o desenvolvimento do presente estudo a compreensão das diferentes histórias de vida, focando nas práticas dos sujeitos, mediante a compreensão de que elas dizem respeito a relação estabelecida entre sujeito e sociedade ${ }^{2}$. Dessa forma, nesta categoria as histórias de vida dos colaboradores Raul, Guimarães, Galeano e Bob - e da colaboradora - Ana - serão brevemente apresentadas, mas também estarão presentes em toda a discussão trazida.

\section{Raul}

Raul é um homem de 41 anos, natural da cidade do interior de Pernambuco em que a pesquisa se deu. Quando adolescente, mudou-se para outras cidades com familiares, indo depois morar só em São Paulo, na favela da Cubica. Local que afirmou ter sofrido muita violência policial, retornando para sua cidade natal aos 19 anos. Aos 13 anos de idade, fazia uso de álcool e maconha, posteriormente o uso de crack. Contou que durante um período de interrupção do uso das substâncias teve um "surto", recebendo o diagnóstico de esquizofrenia.

Raul passou cinco anos e seis meses em um manicômio judiciário, afirmando que isso é passado e que atualmente "sobrevive" um dia de cada vez. Tem dois filhos do seu antigo casamento e uma filha de outra relação, aos quais afirma ser muito apegado.
Ainda de acordo com o seu relato, a arte esteve sempre muito presente na sua vida, primeiramente nas músicas de rock que tanto gosta, e depois na escrita de poesias. Prática que trouxe ajudar na lida com a monotonia e a depressão, segundo ele relacionadas às recorrentes tentativas de suicídio.

\section{Guimarães}

Guimarães tem 35 anos e atualmente trabalha como "flanelinha". Veio de Minas Gerais, onde seu último trabalho foi em uma sapataria. É usuário de crack, álcool e maconha, tendo iniciado o uso de substâncias aos oito anos de idade. Contou sobre já ter sido encarregado de uma multinacional em Recife-PE, interpelando-me sobre: "Nem parece, né? Eu era o exemplo". Afirmou ter sido demitido após ser diagnosticado com HIV. Falou sobre o desejo de ter uma família, trazendo na lembrança o falecimento da mãe, a quem era muito apegado, e posteriormente do pai, que era policial e com quem ele mantinha uma relação conflituosa. Nesse mesmo período, separou-se da ex-companheira, com quem tem duas filhas, e se mudou para casa de tias em Recife-PE, cidade em que passou cinco anos internado em uma comunidade terapêutica.

Após sair da comunidade terapêutica, casouse e teve um filho que foi proíbido de ver por causa do diagnóstico de HIV, afirmando ser essa "a maior dor" da sua vida. Diante desse contexto, mudou-se para uma cidade no interior de Penambuco, a convite de um amigo, sendo internado em uma comunidade terapêutica após uma tentativa de suicídio. Está em situação de rua desde que saiu da instituição, há quatro anos. Atualmente, passa grande parte do seu dia no "ponto" em que trabalha como flanelinha, espaço em que estabeleceu relações com os comerciantes das redondezas, que sempre o chamam para pequenos trabalhos.

Contou que começou a "praticar a redução de danos", reduzindo o número de pedras de crack fumadas durante o dia, substituindo-as pelo álcool e pela maconha. Dentro desse contexto, alugou uma "casinha" com outra pessoa em situação de rua, poucos dias antes do início das entrevistas, apontando a importância do acontecido para o seu cuidado, visto que era no período da noite que o uso de substâncias era mais frequente.

\section{Galeano}

Galeano, atualmente com 60 anos, é natural da cidade do interior do Pernambuco onde esta 
pesquisa ocorreu. Foi para São Paulo aos 17 anos, atribuindo o fato ao envolvimento em uma "confusão", e desde então circulou por várias cidades, indo de uma a outra andando, pedindo caronas ou passagem.

Morou um período no Mato Grosso, de onde se mudou após o falecimento da mãe, indo para Cuiabá, onde conheceu sua antiga companheira, que também faleceu pouco tempo depois. Relacionou essas perdas ao início do uso da "base, o produto que faz o crack e a cocaína”. Entretanto, referiu-se apenas ao álcool e ao tabaco ao falar sobre o uso de drogas atualmente.

Mencionou a importância do Centro de Atenção Psicossocial álcool e outras drogas (CAPS ad) da cidade para o seu processo de cuidado, citando a Redução de Danos e a viabilização de alguns direitos, como o Passe Livre. No momento, está afastado do serviço pelo envolvimento em uma "confusão" com outra pessoa que também faz acompanhamento. Sua relação com igrejas foi também trazida, referindo a essas vivências processos de abstinência e retorno do uso de drogas.

Tem uma filha pequena, que no momento se encontra sob os cuidados da sua sogra, devido a mãe da criança estar em uma comunidade terapêutica, falando sobre a dificuldade de poder ver a filha. Durante a entrevista, trouxe também o aluguel recente de um casa que está dividindo com Guimarães.

\section{Bob}

Bob tem 35 anos, é de Lagoa Grande, cidade do interior do Pernambuco, e atualmente trabalha como flanelinha. Foi "criado" pela a avó, que faleceu quando ele tinha nove anos, ficando sobre os cuidados das tias. Aos 15 anos, pediu de presente a uma das tias conhecer a mãe, descobrindo que a mesma vivia em condições precárias e com mais nove filhos. Dessa forma, permaneceu com as tias, indo aos 16 anos de idade morar no Maranhão com o pai, onde ficou por 12 anos.

Relacionou o início da prática de roubos à "falta de orientação e de apoio" do pai, sendo preso várias vezes até ser institucionalizado, cumprido medida socioeducativa por nove meses. Um ano após ter cumprido a medida, foi sentenciado a nove anos na penitenciária de Pedrinhas que, segundo ele, é um dos presídios mais violentos da America Latina, onde aprendeu a fazer uma droga que, na época, era chamada Merla.

Refere que a relação com o pai piorou após ser solto e que os outros familiares não querem saber dele, destacando-se a recorrência do relato de situações semelhantes durante o período de estágio no CnaR. Retornou para Pernambuco, estando há sete anos na cidade sede desta pesquisa, com intensificação do uso de drogas e há quatro anos "parado" no local onde trabalha. Outras pessoas em situação de rua ficam nesse espaço, conhecido entre eles como "favelinha", onde dormem, trabalham e fazem uso de drogas.

Ana

Ana é uma mulher de 37 anos, geralmente fica em uma feira livre, onde se encontra outras pessoas em situação de rua. Entre elas, Victor (nome fictício), a pessoa com quem Ana se relaciona há 19 anos. Foi a única mulher que consegui entrevistar, dificuldade que possivelmente tem a ver com o menor percentual de mulheres nessa situação quando comparado ao número de homens, como já apontado pelo "Primeiro censo e pesquisa nacional sobre a população em situação de rua"6. Entretanto, destaca-se que na rotina do serviço se via uma maior dificuldade em falar sobre si entre elas, o que atravessou a escolha dos sujeitos para a pesquisa.

No momento da entrevista, Ana se encontrava em um quadro de fragilização decorrente da prisão de Victor. Ele cumpria medida devido às agressões físicas contra ela, de modo que na ocasião sentia-se culpada pela situação. Diante do quadro de fragilização apresentado, a entrevista com Ana precisou ser interrompida e não foi possível acessá-la em outros momentos com esse objetivo.

Apesar dos relatos sobre as agressões constantes contra Ana serem sempre trazidos nos atendimentos com o CnaR, tanto físicas como verbais, Victor é também colocado por ela como seu "protetor". Relaciona-se com ele há 19 anos, tendo duas filhas e um filho com o mesmo, os quais perdeu a guarda.

Atualmente, a filha mais velha reside com a avó de Ana em outra cidade no interior de Pernambuco, e as outras duas crianças moram com o pai e a mãe de Victor, contexto que Ana sempre traz como algo que lhe gera sofrimento, mediante a dificuldade em ver as crianças. Durante a entrevista, a perda da guarda das filhas e do filho, a perda de familiares e a quebra de vínculos com eles foram constantemente trazidas, sendo relatado o sentimento de solidão, o que relacionou ao uso problemático do álcool.

O único vínculo familiar que Ana ainda mantém é com o avô, de modo que sua rotina se alterna entre os períodos em que fica na feira e/ou 
na casa dele. Entretanto, traz a dificuldade em se manter na residência do mesmo devido à falta de alimentação e a solidão.

O relato de Ana e dos outros colaboradores apontam para o que traz a literatura ao falar sobre como a situação de estar na rua e/ou sobrevivendo dela é antecedida por uma sobredeterminação de fatores de difícil apreensão. Essas são transversais a história de vida de cada sujeito, dando-se enquanto uma "deriva marginal" ${ }^{15}$.

Compreendendo-se essas desigualdades sociais a partir de Robert Castel ${ }^{23}$, pode-se falar em "desidentidade" social ou desfiliação, percepção que reitera as dinâmicas de exclusão enquanto anteriores aos efeitos completamente dessocializantes de marginalização dos sujeitos.

Nesse sentido, faz-se importante compreender os determinantes que atravessam os processos de marginalização. Ao falar sobre a sua trajetória, Raul traz em seu discurso uma das questões sociais centrais ao fenômeno da PSR no Brasil, apontando o racismo e a organização social advinda dele como a causa de empobrecimento de grande parcela da população: "É a pirâmide social: lá em cima tá a grana toda, e já embaixo nada, e a maioria são negros" (Raul).

Aponta-se, assim, como o Brasil "passou de um mercado de trabalho escravocrata para formalmente livre, mas manteve todas as virtualidades do escravismo na nova situação". Esse acordo de classes reverbera no racismo estrutural que historicamente atravessou a conformação da sociedade brasileira, repercutindo decisivamente nos números da $\mathrm{PSR}^{24}$. A Pesquisa Nacional sobre a População em Situação de Rua ${ }^{6}$ expressa essa realidade ao apontar a acentuada discrepância entre o número de pessoas negras (pretas e pardas) (67\%) e o número de pessoas brancas $(44,6 \%)$ dentro desse recorte, fato também observado na cidade em que esta pesquisa foi realizada.

Diante do exposto, vê-se que são múltiplas as razões que levam as pessoas a viverem $\mathrm{da} / \mathrm{na}$ rua, sendo todas elas expressivas da relação com um processo de perda ou ruptura. Essas são reatualizadas no cotidiano, de forma que novos rompimentos são impostos e a necessidade de tessitura de outros trajetos, materializados no lugar inventado ${ }^{5}$.

\section{Drogas, medicalização de problemas sociais e controle}

Este eixo propõe-se a falar sobre o uso de drogas entre a PSR, trazendo os diversos sentidos atribuídos e as relações estabelecidas dentro do contexto sócio-histórico em que esse fenômeno se constitui. Parte-se da percepção trazida por Antônio Nery ${ }^{25}$ ao abordar o consumo de substâncias enquanto uma questão humana, referente às suas necessidades subjetivas e sociais. Nesse sentido, aponta a importância da compreensão das relações que se estabelecem com o uso da droga a partir dos "buracos/faltas" (p.20) que constituem a história de cada sujeito.

Maria Rita Kehl ${ }^{26}$, ao fazer essa discussão, traz a necessidade de fuga de todos os sujeitos para suportar a realidade, o que considera o uso problemático de drogas enquanto um sintoma que evidencia a problematização de todas as relações na vida contemporânea. Aponta-se, ainda, que essa prática faz parte de uma das tessituras que compõem o processo de estar na rua, implicando meios de sociabilidade e formas de lidar com a fome e enfrentar dificuldades psicossociais ${ }^{27}$.

Compreensões presentes nas falas dos colaboradores e da colaboradora da pesquisa, em que o fato de estar em situação de rua há muitos anos, a fome, a humilhação muitas vezes sofrida, perdas de familiares a da guarda dos filhos, a ruptura de vínculos e a solidão foram trazidas como motivação para o uso, como afirma Guimarães no trecho: “[...] sinto saudade, fico triste, dá vontade de me matar, escuto vozes, vejo coisas, então eu prefiro usar e beber porque eu esqueço as vozes e não vejo nada, através da droga e da cachaça corta tudo isso e mata um pouco a minha dor".

É imprescidível considerar a unicidade da relação existente entre qualquer substância e a pessoa que a usa ${ }^{28}$, sendo fundamental compreender as subjetividades e os contextos socioculturais em que o consumo ocorre ${ }^{29}$. Esse contexto sociocultural diz respeito ao meio físico, social e cultural, enunciado enquanto o "setting" onde se dá o uso da droga ${ }^{30}$.

As variáveis sociais e os modos de controle que compõem o "setting" repercutem nos efeitos relacionados a utilização da droga e as consequências sociais dessa prática ${ }^{30}$. Dessa forma, conhecendo o contexto em que os sujeitos experienciam a utilização da substância, é possível compreender as experiências vivenciadas por eles, que refletem ou estão relacionadas aos cenários sociais ${ }^{31}$.

Para além das doses e do caráter farmacológico das drogas, as ideias e crenças formadas em relação a elas também influenciam nos seus efeitos subjetivos. Nesse sentido, desdobram-se sobre os modos de uso a interpretação dos seus efeitos e os modos de lidar com as consequências da experiência ${ }^{31}$. 
Diante do exposto, é importante refletir sobre como os discursos negativos referentes ao crack atravessam a relação da PSR com essa droga, considerando que muitos usuários dessa substância se identificam a essas premissas ${ }^{32}$. Dos quatro informantes do sexo masculino, todos referiram utilizar múltiplas substâncias, já tendo feito ou fazendo uso do crack.

Em todos os diferentes contextos que referiram a inserção do crack em suas práticas de consumo, trouxeram uma perspectiva bastante negativa em relação a droga, visão que não necessariamente foi trazida em relação as outras substâncias, como pode ser evidenciado nos seguintes trechos: "É muito violento esse crack, veio pra derrotar muita gente, quem entra nesse crack demora mesmo a sair, demora muito, porque é muito viciante” (Raul); “[...] aí vim pra cá reduzir meus anos, porque eu não usava crack, aí comecei a usar crack aqui” (Galeano); "Tem coisas simples que a droga [crack] faz você esquecer e tem um certo tempinho que você larga a vida da droga e você começa a enxergar verdadeiramente o que você se tornou" (Bob).

Antônio Nery ${ }^{29}$ aponta determinantes estruturais como o grande elemento produtor dos efeitos desastrosos do crack, trazendo o trabalho da mídia em divulgar questões relacionadas a miséria e a violência, sem trazer, entretanto, a natureza social do problema. De forma que se foca em fenômenos como o uso do crack entre camadas da população excluídas pelo modelo socioeconômico atual a partir do lugar de patologias individuais.

Dessa forma, desconsidera-se a realidade em que vive grande número dos sujeitos atingidos ${ }^{32}$. Não se diz também sobre como as sensações causadas pelo uso são "experiências altamente subjetivas, incentivadas pelo imaginário social que reivindica imediatez, extremo prazer, risco, vertigem, velocidade para nossas vidas" ${ }^{31}$.

Processos que contribuem para formas de assujeitamento desse público, a partir da construção imagética do lugar de capturados pela droga. Mata-se socialmente esses sujeitos, de forma que "recorrerem ainda mais à droga, afrontando a sociedade, em plena luz do dia". (p. 16) ${ }^{32}$.

Realidade apontada pelos interlocutores em falas como a de Bob, ao trazer que "a sociedade quer que você esteja pronto a se reintegrar, mas ela nunca tá pronta pra lhe aceitar”, e de Raul, que aponta o viés racista dessas práticas as quais pessoas empobrecidas são submetidas:

Por que que só o pobre que mora na favela, mora nos guetos é que são desse jeito, discrimina- dos? [...]. O que falta sabe o que é? Oportunidade, que eles mesmo não dão, entendeu? É a pirâmide social, lá em cima tá a grana toda, e já embaixo nada, que a maioria são negros [...] E aí, é desse jeito para sempre? (Raul)

Em contraposição às diversas medidas de controle sobre o corpo individual e coletivo, a RD propõe olhar para a singularidade das pessoas que fazem uso de drogas. Nesse sentido, valoriza o protagonismo dos atores sociais, contrapondo-se a medicalização da assistência por meio da promoção da autonomia e emancipação de sujeitos e grupos ${ }^{33}$.

\section{Redução de danos, singularidades e produção de cuidado no território}

Durante a prática no Consultório na Rua (CnaR), eram constantes os discursos da PSR sobre a dificuldade de acesso aos serviços de saúde. Dificuldade também experienciada nas articulações do CnaR com outros serviços para a garantia de um cuidado integral.

As problemáticas em relação à assistência parecem se agravar entre a PSR que faz uso de drogas mediante o duplo processo de estigmatização que ela sofre. De forma que os serviços de saúde recorrentemente reproduzem modos de marginalização, ao colocarem esta população à margem, negligenciando o seu processo de cuidado ${ }^{7}$.

Diante disso, visando ampliar o acesso da PSR aos serviços de saúde, em 2011 é instituído o CnaR pela Política Nacional de Atenção Básica $(\mathrm{PNAB})^{34}$. Serviço que compõe uma rede intersetorial, em que é inserido com a intenção de produzir uma terapêutica singular para pessoas em situação de rua ${ }^{35}$. Modos de produção de cuidado trazidos nas entrevistas por meio de falas como: "Tem o pessoal do CnaR que gosta da gente, chega junto [...] não tem frescura de falar com a gente, o pessoal que conversa, senta, dá um abraço, um sorriso. Poxa, é tão bom você se sentir acolhido mesmo tando na rua” (Raul); "Tudo que preciso eles vem atrás de mim, sou dependente químico, bebo cachaça, faço uso de drogas [...] nunca me julgaram pelo que eu sou [...] Minha vida não é fácil, mas eles me ajudam em tudo, verbalmente, fisicamente, psicologicamente" (Guimarães).

Nas práticas do CnaR se intensifica a necessidade de lidar com a imprevisibilidade que a todo tempo invade as rotinas dos serviços de saúde, relacionada ao "encontro com histórias de vida em contextos angustiantes no seu próprio desenro-

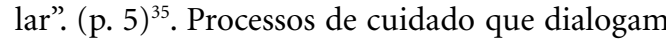
com o meio físico, social e cultural em que se dá 
o uso, o "setting" trazido por Norman Zinberg ${ }^{30}$, possibilitando a compreensão da unicidade da relação entre o sujeito e suas práticas de uso.

São ações que se desenrolam no território, em contato com o espaço relacional dos sujeitos, lidando com a produção de sentidos forjada nas tessituras entre os cenários naturais e a história social $^{36}$. As aproximações desses territórios extrapolam o contexto físico, possibilitando a compreensão dos valores sociais, econômicos, políticos e culturais que atravessam os diferentes territórios existenciais ${ }^{36}$.

$\mathrm{Na}$ assistência a pessoas que fazem uso problemático de drogas, é de fundamental importância se considerar a cultura e o conhecimento dos mundos locais de significado para a oferta do cuidado. É a partir disso que se faz possível o delineamento de problemáticas e objetivos concretos, que dialoguem com as diferentes realidades e sujeitos ${ }^{37}$. Esse modo de produção de cuidado diz de uma abordagem participativa, trazendo a importância dos diferentes atores envolvidos no processo terem voz, possibilitando a identificação de problemas e critérios de abordagem ${ }^{38}$.

É dentro dessa perspectiva que se faz possível a construção de práticas em que a partir do encontro são possíveis modos de singularização. Esses permitem que sejam construídos novos territórios e novos sentidos dentro dos processos de cuidado. Cria-se, assim, a possibilidade de intervenções baseadas nas diferentes formas de consumo e grupos de consumidores, produzindo processos de autonomia e certo "nível de autocontrole" ${ }^{35}$. Construções trazidas nos discursos de Guimarães e Bob ao falarem sobre as singularidades presentes nas estratégias de cuidado construídas no cotidiano:

Antigamente eu usava 30 a 40 pedras por dia, hoje se eu usar duas ou três é muito, mas meu negócio hoje é a cachaça [...] eu sinto mais efeito cola- teral, mas eu me alimento melhor, durmo melhor. E hoje eu tô deixando a cachaça pra ficar livre. $O$ cigarro eu já deixei mais, eu fumo um ou dois cigarros por dia [...] também notei que eu não posso fumar maconha, que eu sou esquizofrênico, quando eu fumo maconha eu passo mal, então evito, mas de vez em quando eu dou umas bilinhas porque dá fome. Antigamente eu pesava $51 \mathrm{~kg}, 48 \mathrm{~kg}$, hoje eu to pesando uns $78 \mathrm{~kg}$. (Guimarães)

Geralmente eu tenho meu material de uso, eu dificilmente compartilho o cachimbo, não tomo pico (além de ser muito perigoso é uma droga que é mais cara), mas sempre quando aparece a oportunidade, que a equipe do CnaR vem, eles abre a oportunidade pra fazer exame pro cara ver se tem alguma contaminação, pegou algum vírus ou algo do tipo assim, eu sempre faço, porque por mais que eu tenha o cuidado, eu vou usar droga e não vou estar em meu estado normal. (Bob)

\section{Considerações finais}

Mediante o exposto, destaca-se a importância de refletir sobre a PSR usuária de drogas para além das lentes da normatividade dicotômica que organizam o espaço e os territórios existenciais. Para a construção de processos de cuidado, é preciso olhar para "o processo de recriação nas extremidades", movendo compreensões sobre modos de vida que fogem a lógica de mundo hegemônica.

Possibilidades que só podem ser concretizadas no território, em que se faz possível a compreensão das especificidades da PSR e encontros que permitem processos de singularização. É preciso estar aberto ao encontro com a desterritorialização dos sentidos e das práticas para a reinvenção de um cuidado que produza vida no espaço da rua. 


\section{Colaboradores}

LS Marques trabalhou na concepção, delineamento, interpretação dos dados, redação do artigo e aprovação da versão final a ser publicada. JHM Costa trabalhou na concepção, delineamento, revisão crítica e aprovação da versão final a ser publicada. MM Gomes trabalhou na concepção, delineamento, revisão crítica e aprovação da versão final a ser publicada. MM Silva trabalhou na concepção, delineamento, revisão crítica e aprovação da versão final a ser publicada.

\section{Referências}

1. Silva GD, Lemos FCS, Galindo D, Bicalho PPG. Corpos, cidades e subjetividades: resistências no tempo presente. In: Lemos FCS, Galindo D, Bicalho PPG, Arruda P, Lima BJM, Moreira MM, Guerra JD, Nogueira JC, Souza LC, Ueyama F, Mendes LA, Trujillo DHS, Garcia BM, organizadores. Conversas transversalizantes entre psicologia política, social-comunitária e institucional com os campos da educação, saúde e direitos. Curitiba: CRV; 2017. p. 283-292.

2. Nobre MT, Moreno NS, Amorim AKMA, Souza EC. Narrativas de modos de vida na rua: histórias e percursos. Psicol Soc 2018; 30(175636):1-10.

3. Mattos RM, Ferreira, RF. Quem vocês pensam que (elas) são? Representações sobre as pessoas em situação de rua. Psicol Soc 2004; 16(2):47-58.

4. Goffman E. Estigma: notas sobre a manipulação da identidade deteriorada. $4^{\text {a }}$ ed. Rio de Janeiro: LTC 1981.

5. Nobre MT, Barreira IAFA. Reinvenção de si no mundo da rua: trajetos e narrativas de quem nela vive. Interação em Psicologia 2018; 22(3):200-210.

6. Ministério do Desenvolvimento Social e Agrário (MDS). Primeiro censo e pesquisa nacional sobre a população em situação de rua. Brasília: MDS; 2008.

7. Silveira GL, Rodrigues LB. O consumo de substâncias psicoativas e o autocuidado entre pessoas em situação de rua na cidade de Juazeiro-BA. Psicologia, Diversidade e Saúde 2013; 2(1):95-122.

8. Foucault M. História da loucura na idade clássica. São Paulo: Perspectiva; 1978

9. Merhy E. Anormais do desejo: os novos não-humanos? Medicalização e biopolítica- Sinais que vem da vida cotidiana e da rua. In: Collares CAL, Moyses MAA, Ribeiro MCF, organizadores. Novas capturas, antigos diagnósticos na era dos transtornos. $1^{\mathrm{a}} \mathrm{ed}$. Campinas: Mercado de Letras; 2013. p. 221-232

10. Escohotado A. A História Elementar das Drogas. $1^{\text {a }}$ ed. Lisboa: Antigona; 2004.

11. Brasil. Portaria ${ }^{\circ} 3.088$ de 23 de dezembro de 2011. Institui a Rede de Atenção Psicossocial para pessoas com sofrimento ou transtorno mental e com necessidades decorrentes do uso de crack, álcool e outras drogas, no âmbito do Sistema Único de Saúde (SUS). Diário Oficial da União 2011; $23 \mathrm{dez}$.

12. Brasil. Portaria no 2.197 de 14 de outubro de 2004 . Redefine e amplia a atenção integral para usuários de álcool e outras drogas, no âmbito do Sistema Único de Saúde - SUS, e dá outras providências. Diário Oficial da União 2004; 14 out.

13. Brasil. Decreto no 9.761 de 11 de abril de 2019. Aprova a Política Nacional sobre Drogas. Diário Oficial da União 2019; 11 abr.

14. Guimarães TA, Rosa LCSA. A remanicomialização do cuidado em saúde mental no Brasil no período de 2010-2019: análise de uma conjuntura antirreformista. O Social em Questão 2019; 22(44):111-138.

15. Frangella SM. Corpos urbanos errantes: uma etnografia da corporalidade de moradores se rua em São Paulo [tese]. Campinas: Universidade Estadual de Campinas; 2004.

16. Souza FF, Zambenedetti G. Percursos de cuidado: pistas sobre itinerários terapêuticos em saúde mental. Tempus Actas Saude Colet 2017;11(4):105-122. 
17. Minayo MCS. Pesquisa social: teoria, método e criatividade. $21^{\mathrm{a}}$ ed. Petrópolis: Editora Vozes Limitada; 2011.

18. Flick U. Entrevista Episódica. In: Bauer MW, Gaskell G, organizadores. Pesquisa qualitativa com texto, imagem e som. Um manual prático. Petrópolis: Vozes; 2002. p. 114-136.

19. Jovchelovitch S, Bauer M. Entrevista Narrativa. In: Bauer MW, Gaskell G, organizadores. Pesquisa qualitativa com texto, imagem e som. Um manual prático. Petrópolis: Vozes; 2002. p 90-114.

20. Chiesa CD, Fantinel L. Quando eu vi, eu tinha feito uma etnografia: notas sobre como não fazer uma "etnografia acidental “. In: Anais do Encontro de Estudos Organizacionais da ANPAD, 2014; Gramado/RS. p. $1-16$.

21. Silva DG, Lemos FCS, Galdino D. Corpos em situação de rua: entre práticas de normalização e resistência. Contemporâneo 2016; 6(2):467-484.

22. Brasil. Decreto de lei no 7.053 de 23 de dezembro de 2009. Institui a Política Nacional para a População em Situação de Rua e seu Comitê Intersetorial de Acompanhamento e Monitoramento e dá outras providências. Diário Oficial da União 2009; 23 dez.

23. Castel R. A dinâmica dos processos de marginalização: da vulnerabilidade a "desfiliação". Caderno CRH 1994; 10(26):19-40.

24. Souza J. A elite do atraso: da escravidão à lava jato. $1^{\text {a }}$ ed. Rio de Janeiro: Leya; 2017.

25. Nery Filho A. Introdução: Por que os humanos usam drogas? In: Nery Filho A, Macrae E, Tavares LA, Nuñez ME, Rêgo M, organizadores. As drogas na contemporaneidade: perspectivas clínicas e culturais. Salvador: EDUFBA: CETAD; 2012. p. 11-20.

26. Café Filosófico [programa de televisão]. São Paulo: TV Cultura; 2014

27. Costa APM. População em situação de rua: contextualização e caracterização. Texto Contexto 2006; 4(1):115.

28. Corrêa G. Drogas para além do bem e do mal. In: Santos LMB, organizadora. Outras palavras sobre o cuidado de pessoas que usam drogas. Porto Alegre: Ideograf; 2010. p. 167-176.

29. Nery Filho A, Soares GG, Nunez ME, Macrae, E. Diálogo com Dr. Antonio Nery Filho, George Gusmão Soares, Maria Eugênia Nuñes e Edward Macrae sobre o crack. In: Macrae E, Tavares LA, Nuñez ME, organizadores. Crack: contextos, padrões e propósitos de uso. Salvador: EDUFBA; 2013. p. 27-58.
30. Zinberg N. Drug, set, and setting: thebasis for controlledintoxicant use. Yale: Yale University Press; 1984.

31. Nuñez ME. A chegada do crack em Salvador: quem disse que o crack traz algo de novo? In: Macrae E, Tavares LA, Nuñez ME, organizadores. Crack: contextos, padrões e propósitos de uso. Salvador: EDUFBA; 2013. p. $135-170$

32. Macrae E. Prefácio. In: Macrae E, Tavares LA, Nuñez ME, organizadores. Crack: contextos, padrões e propósitos de uso. Salvador: EDUFBA; 2013. p. 11-26.

33. Gomes TB, Vecchia MD. Estratégias de redução de danos no uso prejudicial de álcool e outras drogas: revisão de literatura. Cien Saude Colet 2018; 23(7):23272338.

34. Brasil. Portaria no 2.488 de 21 de outubro de 2011. Aprova a Política Nacional de Atenção Básica, estabelecendo a revisão de diretrizes e normas para a organização da Atenção Básica, para a Estratégia Saúde da Família (ESF) e o Programa de Agentes Comunitários de Saúde (PACS). Diário Oficial da União 2011; 21 out.

35. Londero MFP, Ceccim RB, Bilibio LFS. Consultório de/na rua: desafio para um cuidado em verso na saúde. Interface (Botucatu) 2014; 18(49):251-260.

36. Lima EMFDA, Yasui S. Territórios e sentidos: espaço, cultura, subjetividade e cuidado na atenção psicossocial. Saude Debate 2014; 38(102):593-606

37. Lancetti A. Contrafissura e plasticidade psíquica. $1^{\text {a }}$ ed. São Paulo: Hucitec; 2015.

38. Romaní O. Políticas de drogas: prevención, participación y reducción del daño. Salud Colect 2008; 4(3):301-318.

Artigo apresentado em 31/10/2020

Aprovado em 11/10/2021

Versão final apresentada em 13/10/2021

Editores-chefes: Romeu Gomes, Antônio Augusto Moura da Silva 